\title{
Pensar a Química

\author{
Bachelard e o Materialismo \\ Racional
}

Raquel M.C. Gonçalves ${ }^{a}$

\author{
«A Química é uma ciência de futuro \\ por ser, cada vez mais, \\ uma ciência que abandona o seu passado..."
}

G. Bachelard,

«Le Matérialisme Rationnel»

Um racionalismo inflexível e sereno dominou toda a doutrina epistemológica de um dos grandes pensadores multifacetados do século XX, Gaston Bachelard (1884-1962), sobre o qual Dagognet afirmou: "(...) o pensamento dinamizava a sua vida e não o inverso" [1]. Bachelard nasceu em Bar-sur-Aube, na província de Champanhe, em França. Exerceu funçð̃es administrativas no Correio local e, simultaneamente, completou a Licenciatura em Matemática.

Foi durante os dez anos que se seguiram ao termo da Primeira Guerra Mundial, enquanto professor de ensino secundário no colégio da sua terra natal, que Bachelard, em consequência de lhe ser exigido o ministrar de diversificadas disciplinas, entrou em contacto com a Filosofia e sentiu o estímulo para uma profunda dedicação aos problemas da Epistemologia. Em 1928, publicou os seus primeiros ensaios neste dominio: «Ensaio sobre o conhecimento aproximado» (tese de Doutoramento de Estado) e «Estudo sobre a evolução de um problema da Física: A propagação térmica nos sólidos” [2,3]. Em 1930, passou a integrar o quadro docente da Faculdade de Letras da Universidade de Dijon e, depois de 1940, o da Sorbonne em Paris.

De entre os seus escritos sobre Filosofia das Ciências salientam-se: "O valor indutivo da relatividade» (1929), "O pluralismo coerente da Química moderna" (1932), "O novo espirito científico" (1938), "A formação do espírito científico» (1938), "A filosofia do não» (1940), "O racionalismo aplicado" (1949), "A actividade racionalista da Fisica contemporânea" (1951) e "O materialismo racional» (1953) [4-11]. A uma dinâmica intelectual poderosa, associava uma visão clara da natureza complexa e complementar do espírito do homem. De facto, Bachelard surpreende-nos na sua totalidade: lado a lado com a criacão e desenvolvimento do Materialismo Racional - Filosofia científica de verdade coerente, ainda que múltipla e renovável, de construção da ciência e das suas aplicaçðes - o filósofo dedicou-se ao estudo do imaginário, dos sonhos e devaneios.

Em oposição ao semi-mundo humano racional, completando-o, Bachelard colocou o semi-mundo onírico, onde o insólito e a contradição, "o leite negro", "a água seca» e "o fogo frio", funcionam como imagens criadoras e vivificantes da mente.

A qualidade da sua obra no dominio da Arte e da Psicanálise merece relevo. Na Epistemologia, porém, o seu trabalho foi ainda mais notável.

\section{O Materialismo Racional}

Entre sistemas filosóficos tradicionalmente adversos, o Idealismo e o Realismo, a meio caminho, na posição de suprema eficiência para o vivo progresso do conhecimento científico, eis o ponto onde Bachelard pretendeu localizar a sua doutrina epistemológica: o Materialismo Racional.

Idealismo e Realismo são entendidos pelo epistemólogo como filosofias do imediato - do espírito, das ideias, a primeira, das impressð̃es e sensaçð̃es, a segunda - ambas menosprezando componentes de eficácia inerentes ao pensamento produtor da ciência.

A ciência contemporânea deve adjectivar-se de actual - activa, plural e em permanente renovação - , não se coadunando com imediatismos, nem com o pendor exclusivo de ser pensante, de ideias a priori e confirmaçð̃es experimentais, nem com simples acumulaçð̃es de factos sem quaisquer interpretaçס̃es ou teorizaçס̃es.

Parece-nos interessante explicitar com algum detalhe o sentido em que aqui são aplicados, tentando não adulterar a significação bachelardiana, os termos Idealismo e Realismo.

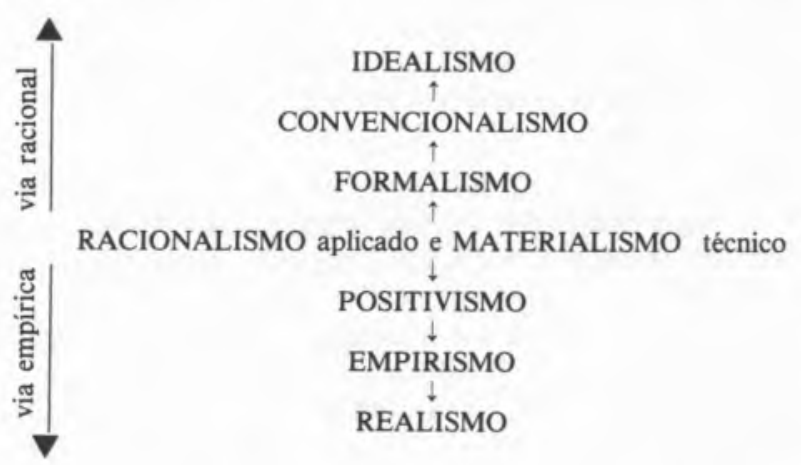

O Idealismo filosófico caracteriza-se por considerar como centro de análise o sujeito (a consciência, o eu), em permanente interrogação sob as formas de conhecimento. O Idealismo do período moderno começou com Descartes e engloba as doutrinas de Leibniz, Kant, Fichte, Schelling e Hegel, entre outros; neste contexto, é comum justapô-lo ao Racionalismo, embora possam considerar-se excepçð̃es: Espinosa insere-se entre os racionalistas sem ser idealista e Berckeley, de vertente empirista, é simultaneamente idealista, ainda que de um modo subjectivo.

Todas as formas de Idealismo pretendem compreender o ser (o dado da consciência, o pensamento), sem que isso signifique, necessariamente, que a realidade se reduza ao sujeito. $\mathrm{O}$ conhecimento, segundo os idealistas, transcende a experiência e fundamenta-se na razão. Assim, o universo exterior não é cognoscível por utilização simples dos sentidos, pelo uso da sensibilidade; só a razão tem a capacidade de conhecer.

O Realismo filosófico, no domínio da teoria do conhecimento, advoga serem os dados dos sentidos, e nunca o sujeito, o que fundamenta o conhecimento. Em consequência, e ao contrário do Idealismo, é possível conhecer sem supor que o sujeito condiciona (a priori) esse mesmo conhecimento.

Num sentido restrito, Realismo confunde-se com certa forma de Positivismo: o conhecimento consiste na

\footnotetext{
a Faculdade de Ciências de Lisboa - CECUL, Calçada Bento da Rocha Cabral, 14, 1200 Lisboa.
} 
investigação dos factos e das relações entre eles; nem especulaçōes, nem teorias compõem o conhecimento. O Realismo científico contemporâneo mantém as características empíricas, mas encontra-se já muito afastado da noção primitiva de ser o conhecimento a reprodução fiel da realidade exterior.

O Realismo primitivo (natural) deu lugar ao Realismo crítico, segundo o qual, o dado só será verdadeiramente conhecido após o seu exame racional, auxiliado pela lógica formal simbólica.

Os atomistas e os neo-positivistas, como Bertrand Russell e os filósofos do "Círculo de Viena" (Schlick, Neurath, Carnap) incluem-se na atitude filosófica realista contemporânea.

A Epistemologia de Bachelard recusa uma doutrina prévia face aos acontecimentos, uma doutrina que se limite a procurar nos factos a confirmação de uma actividade do espírito ou da inteligência; recusa, também, uma doutrina que mantenha o conhecimento ao nível das impressōes e das sensações e que empobreça as potencialidades do pensamento.

O reconhecimento do carácter de saber aproximado da ciência faz com que o real e a razão, o Realismo e o Idealismo, se correlacionem de modo a eliminarem princípios exclusivistas, sistemas prematuros e definitivos.

Pensar a ciência é reflectir sobre a ciência e não determinar a ciência.

O termo Idealismo pode também ser utilizado no sentido de significar uma atitude segundo a qual as acções humanas se regem por ideais, supostamente realizáveis. Nesta acepção, de novo, se lhe opõe o Realismo, corrente que determina ser a actuação do homem função das realidades, dos factos com impacto social.

Embora tenha sido no contexto da teoria do conhecimento, e não da ética ou da política, que os termos Realismo e Idealismo foram escolhidos por Bachelard, é de admitir, no entanto, que a "confusão" assim introduzida seja deliberada, uma vez que acorda com as características de pensador multifacetado do filosofo. O "equívoco» é ainda mais acentuado se tivermos presente que realistas são também os idealistas platónicos e neo-platónicos da doutrina dos universais: as ideias são reais.

A posição central, representada no esquema anterior, conjunção do Racionalismo e Materialismo é, segundo Bachelard, a única que permite uma Filosofia simultaneamente coesa e desdobrada.

O Racionalismo aplicado e o Materialismo técnico não são, contudo, variantes melhoradas das doutrinas iniciais. As suas designaçōes têm a ver com o novo significado de saber científico que Bachelard expos nas suas obras.

Se compreendermos por dado o conjunto dos fenómenos que se encontram imediatamente presentes a um sujeito que conhece [12], torna-se impossível entender, após os modelos atómicos do século XX, o objecto da ciência como um dado (a não ser, por exemplo, que a Física passasse a ser uma ciência "oculta" em consequência dos seus corpúsculos serem um dado oculto). Bachelard, opondo-se ao convencionalismo filosófico, desloca o conceito de objecto da ciência; este, passa a pertencer ao domínio do construido: é um resultado ou um efeito. O conhecimento científico tem, pois, uma natureza diferente da do saber comum: produz-se, progride, é sempre provisório e determina-se pela sua utilidade.

A produção do conhecimento é conseguida por transpo- sição de obstáculos epistemológicos. A intuição e a percepção, subjectivas, contam-se entre estes obstáculos. O seu interesse, porém, não é negado uma vez que podem constituir hipóteses de trabalho.

O Racionalismo a priorístico, prematuro, é, então, substituido por um Racionalismo reflexivo, aplicado o qual não só confere sentido aos encadeados de experiências sugeridas pelas hipóteses de trabalho (fenomenologia de trabalho) como também determina as regiōes do saber científico - organizações racionais correspondentes a sectores particulares do trabalho científico - de acordo com o princípio de progresso do pensamento, «estudo da aplicação de um conceito no próprio significado do conceito" [7].

O conhecimento é assim valorizável, pelo poder de aplicação do Racionalismo, numa estreita simbiose entre a razão e a experiência.

O saber científico é sempre provisório. Reconhecer esta "propriedade» implica entender o sujeito segundo um novo estatuto: o sujeito cientista não é um sujeito de afirmação inicial, antes se encontra empenhado na produção de uma "história» permanentemente inacabada. Implícito, vislumbra-se um novo conceito de história das ciências.

De facto, a história das ciências bachelardiana é não contingente, o seu passado determina-se pelo momento presente e o futuro nunca surge revelado pela história do passado.

Aumentar a história, progredir na ciência, é um processo reaccional que tem por inibidor o hábito. A aparente solidez do permanente estagna o intelecto humano.

A Epistemologia bachelardiana privilegia o não: o imobilismo científico dilui-se pela negação; o não teórico contrói, verifica e correlaciona. E, também, o aproximacionismo: a limitação experimental (instrumental) consciente, abandona aperfeiçoamentos inúteis, rompe com o hábito metodológico e cria verdades superiores. A generalização em ciência é um caminho de superficialidade. A especificação (ou diferenciação), pelo contrário, permite o aprofundamento e a ampliação do conhecimento.

Bachelard classificou a ciência contemporânea de materialista. Deste modo, aceitou, tal como nas filosofias materialistas de cariz espistemológico convencionais, ser a matéria a única realidade científica. Na noção de matéria, porém, incluiu todas as noções referentes às suas propriedades e formas, as de energia e de radiação, por exemplo, num apoio dinâmico aos princípios revolucionários planck-einsteinianos do início do século $\mathrm{XX}$.

É ainda como método de investigação - processo de produção - que deve ser compreendido o Materialismo bachelardiano: o trabalho do cientista é produzir ciência; o objecto da ciência é um conceito tecnicamente realizado.

A importância do carácter técnico da ciência foi largamente sublinhado pelo epistemólogo: os aparelhos de medida e a precisão dos resultados que geram. Ao utilizar a expressão Materialismo técnico, Bachelard reuniu dois aspectos essenciais na produção do saber científico: o aparelho e o objecto da sua medida.

Em resumo, o Materialismo Racional responde satisfatoriamente à actualidade da ciência: porque o saber científico pressupōe a dualidade teoria-instrumento em agregação simbiótica; porque a ciência é uma construção organizada e sempre reorganizável, fruto de mutaçס̃es bruscas e inovadoras provocadas por novas ideias e 
novas experiências; porque encadeamentos de razōes mais sólidas para os factos, a descoberta, é o efeito (o sucesso) de um acto de racionalismo militante.

O Materialismo Racional é uma Filosofia aberta. A fórmula da multiplicidade aplica-se aos objectos e às instâncias do pensamento, aos métodos e às opinið̋es: porque é no diverso que a razão se encoraja, realiza e revigora a ciência.

$\mathrm{O}$ autoritarismo de pais e mestres, a rigidez das certezas transmitidas, os dogmatismos da "experiência de vida» são verdadeiros obstáculos ao progresso do saber. A mobilidade do presente impðe uma educação social de permuta constante do conhecimento entre geraçð̃es, entre pais e filhos, professores e alunos.

A ciência (o investigador, a investigação, a descoberta) e a escola (o professor, o conhecimento, o aluno) são indissociáveis.

$\mathrm{O}$ ensino não deve ser dedutivo, mas perturbante da continuidade, destruidor do hábito e construtor do impulso científico. Não interessa tanto a quantidade do que se ensina como a qualidade do estímulo cultural que é induzido.

A Química contemporânea tem sido das ciências que mais tem corroborado as teses doutrinais de Bachelard: o afastamento do Realismo e do Idealismo do centro de maior eficácia da produção da ciência; o estado de permanente renovação do conhecimento científico; a organização racional da ciência assente na valorização específica do conhecimento $[5,9-11,13]$.

\section{Insuficiências do Realismo e do Idealismo em Química}

A Tabela Periódica dos elementos químicos de Mendéléeff (com a sua ordem cruzada - a duas variáveis: o número atómico e a valência - de períodos, as linhas na horizontal, e de famílias, na vertical) possui uma organização formal de tal modo poderosa que permitiu enunciar as propriedades químicas de certas substâncias simples antes mesmo da sua descoberta material. Assim se vê como a tendência racionalizante em ciência, que inclui a necessidade de ordenar, pode ser produtora dos melhores frutos. Em contrapartida, o Realismo, apoiando-se no objecto-acaso, realiza-se mediante experiências não sistematizadas e fornece um conhecimento inacabado: constata mas não explica. Pelo contrário, uma doutrina que fomenta a sistematização, favorece as ocasiōes e completa o conhecimento.

Também a síntese e a identificação de muitos compostos no domínio da Química Orgânica - hidrocarbonetos, álcoois, aldeídos, cetonas, ésteres, éteres e ácidos carboxílicos - cuja estrutura encadeada foi conhecida anteriormente a muitas das substâncias que preenchem aquelas classes, constitui outro exemplo eloquente dos efeitos da racionalidade em ciência.

E um racionalismo dirigente que mobiliza a experimentação e fertiliza os resultados. Muitas experiências não seriam acto se a sugestão da sua possibilidade e potencialidade não emanasse de um saber racional apriorístico. Assim, a fórmula química de uma substância tem o poder de sugerir deterninadas experiências; tem, também, o poder de impedir outras pelo facto de contabilizar as hipóteses de êxito, o que não aconteceria num esquema empirico, estritamente fenomenal. Razão e experiência são solidárias. O Racionalismo clássico de Kant teria seguramente rejeitado tão íntima associação. Todas as substâncias químicas, simples (elementos) ou complexas (compostos), têm uma estrutura íntima organização de corpúsculos, muitos deles electricamente carregados - que é na sua essência diferente da dos fenómenos, estudados pelos químicos, em que elas participam. A natureza química é sustentada por uma natureza física interior: «o Realismo desconhece a importância da física interna das substâncias» [8].

A teoria dos quatro elementos de Aristóteles foi definitivamente afastada com a descoberta da composição da água, por Cavendish, e do ar, por Lavoisier. O sentido filosófico de tal transformação é intenso: quer a água, quer o ar, perderam a singularidade de ser elemento; as noçőes de líquido e de gás ganharam materialidade face à noção de fluido, espiritualizada, magnética e vital, no pensamento pré-científico. Este materialismo, contudo, cuja dimensão se vai alargando à medida que os resultados das experiências racionalizadas assim o determina, é completamente diferente de um materialismo de exclusiva afirmação inicial.

O oxigénio, fazendo parte da estrutura da água e do ar, é um elemento que tem, todavia, um participação diferente em ambos: quimicamente combinado com o hidrogénio na água; fisicamente misturado com outros gases, azoto, dióxido de carbono, gases nobres, no ar. Muito trabalho teórico e experimental foi necessário desenvolver para se atingir esta conclusão de poucas linhas. Por vezes, transmite-se a ideia de que foi por puro empirismo - electrolisou-se a água acidulada e obteve-se oxigénio e hidrogénio (Cavendish); aqueceu-se óxido de mercúrio e libertou-se oxigénio (Lavoisier). Esta atitude de facilidade é muito negativa no ensino, pois deturpa o processo, escondendo a problemática múltipla em que se promoveu o conhecimento científico.

O Racionalismo, não uno mas diverso permite ao filósofo da ciência (e ao cientista) viver uma pluralidade em benefício do progresso científico.

Diferente dele é o Idealismo unificante, ao avaliar incorrectamente as potencialidades da experimentação e dos seus resultados (a descoberta do oxigénio, por exemplo, provocou graves precipitaçðes; como durante vários anos foi possível extraí-lo de grande número de substâncias, isso valeu-lhe um lugar de soberania na Química e um lugar de princípio organizacional nas doutrinas idealistas.

A Química contemporânea desenvolve-se por duas vias: macroscópcia (fenomenológica) e microscópica (atomística), visando o mesmo objectivo. Esta dupla actividade, de sistematização do conhecimento químico e de estruturação electrónica interpretativa, ambas no sentido contemporâneo de permanente interacção, actualizam a cultura racionalizada. Por isso, a esta dialéctica teoria-experiência deve fazer-se corresponder uma filosofia não dogmática, não univalente, de teses diversificadas e interactuantes.

\section{A Descontinuidade no Pensamento Químico}

Transformar o chumbo em ouro ou em prata foi sonho dos alquimistas. Poder-se-á dizer que tal sonho foi realizado, em pleno século XX, com a descoberta da transmutação dos elementos na Química? Bachelard diz-nos que não: porque a ciência não realiza sonhos nem devaneios; porque o pensamento científico não trabalha as imagens do inconsciente; porque a ciência se produz com ideias e experiências verificadas e precisas.

A Alquimia revela ao estudioso um fascinante mundo onírico. A Química contemporânea não deriva dela sem 
interrupção. "O pensamento científico está essencialmente em estado de revolução permanente" [11].

No exemplo citado da transmutação de elementos metálicos põe-se a claro a inoperância de tal filiação. Para o alquimista a mudança do chumbo para metal nobre era uma alteração fundamentalmente qualitativa, das propriedades físicas cor e massa: um pequena quantidade cinzenta, o chumbo, tornava-se pesada e transformava-se no desejado metal, dourado ou prateado. Para o químico nuclear, porém, o factor activo da transmutação é o número atómico, de 82 no chumbo para 79 no ouro ou 47 na prata. Mas, ainda que atendessemos às massas atómicas - 207 para o chumbo, 197 para o ouro e 106 para a prata - teríamos de concluir que aligeirar o chumbo, e não pesá-lo, nos colocaria mais próximo do objectivo sonhado.

A Alquimia não está na origem da Química. A evocação dos alquimistas conduz-nos a um mundo onírico e misterioso; a dos químicos a um mundo de racionalidade.

O conceito de energia ou de força viva foi polémico, gerador de uma multiplicidade de imagens e de debates confusos até aos primórdios do século XX. Na acepção científica actual, contudo, energia tem completo estatuto científico. Quer a Física, quer a Química, insere-o entre os seus conceitos fundamentais.

A Quimica ao longo dos séculos foi essencialmente uma ciência da matéria: matéria como princípio genérico capital, por vezes reduzida ao significado de massa-quantidade, quantidade indestrutível, conservada através de qualquer reacção ou transformação física.

Assim enunciou Lavoisier o princípio da conservação da massa (matéria): numa transformação química, o somatório da massa dos reagentes e da dos produtos da reacção conserva-se inalterado; matéria como base da singularidade, qualitativa, raiz da distinção e da identificação dos elementos e compostos, em oposição ao carácter quantitivista proposto pelo primeiro juizo de valor. E, em qualquer dos casos, poder-se-á acrescentar que a matéria tem uma energia, uma matéria inerte com uma propriedade, a energia, também inerte.

No espírito do químico de hoje, todavia, estabeleceu-se um verdadeiro existencialismo da energia. Entre a matéria tem e a energia é (e por detrás da energia nada há) existe uma ruptura de pensamento cientifico extraordinária. A energia é a base e a matéria é energia. Este móbil energético que se situa "antes» do fenómeno químico, sendo dele inseparável, abriu alas a uma dinâmica experimentalista florescente, incentivou a procura das suas manifestaçð̃es no domínio da Química. A matéria ganhou actividade, tal qual se deseja para a verdadeira mentalidade científica.

A defesa do continuísmo na cultura científica pode advir de uma inferência incorrecta a partir da continuidade narrativa da história dos acontecimentos. O facto do surgimento de acontecimentos científicos ter sido muito lento nos tempos iniciais de vivência da ciência propriamente dita e esta ter por origem o saber comum, podem igualmente contribuir para a falsa noção de que o progresso da ciência é contínuo e, ainda, de que o conhecimento científico e comum têm as mesmas características. Esta dupla perspectiva, de relaçð̋es invariáveis de sucessão e de similitude no espírito científico, tal como no senso comum, defendida pelo químico e filbsofo Émile Meyerson no seu livro "Identidade e realidade», publicado em 1908, foi severamente criticada por Bachelard [14].
Para Meyerson, o objectivo da ciência, o "compreender", baseia-se em dois princípios interdependentes: o princípio da identidade e o princípio da conservação. A procura da identidade integra o senso comum de causa-efeito e pressupōe a aceitação de tendências invariantes. Meyerson explicou o próprio aparecimento espectacular das teorias relativistas como uma consequência natural do pensamento humano, em conformidade com a sua metodologia, científica ou simplesmente relativa ao sabor comum.

Utilizando as teses de Meyerson, para a elas se opor, Bachelard nega o progresso da ciência alicerçado no carácter idêntico (estático) do intelecto humano e defende a revolução na ciência pela diversificaçâo do idêntico. São estes os termos com que pretende incutir no cientista a vocação da procura do pormenor e do repúdio pela assimilação primária, o resumo didáctico, geral e estagnante. Um enunciado científico geral esconde, segundo Bachelard, a riqueza da particularidade, é redutor e não produtor de ciência. Uma linha de continuidade é sempre incompleta, uma vez que elimina o específico e diminui a qualidade.

As "atmosferas" e "influências", invocadas pelos continuístas para justificar a ocorrência de progressos científicos excepcionais, foram entendidas por Bachelard como diluentes injustificáveis do mérito das ideias e dos génios que as produziram.

A descoberta da radioactividade artificial pelo casal Irene Curie e Frederic Joliot (Prémio Nobel em 1935) causou uma profunda admiração no restrito círculo científico que trabalhava com isótopos radioactivos: «(...) um verdadeiro milagre», foram as palavras utilizadas pelo químico sueco von Hevesy (Prémio Nobel em 1943 pela sua descoberta de indicadores radioactivos) no colóquio "Trocas isotópicas e estruturas moleculares», realizado em Paris, em 1948.

Ainda em 1948, no congresso "A ligação química», promovido pelo CNRS (Centre National de la Recherche Scientifique), Bauer, a propósito da contribuição de Heitler e London para o esclarecimento da ligação de hidrogénio na molécula de água, publicada em 1927, disse: «(...) marca uma autêntica descontinuidade na história da Química».

Dificilmente o recurso a princípios lógicos de identidade e de conservação de tendências poderá explicar o ímpeto incluso nas exclamaçס̃es dos eminentes cientistas que as proferiram, tanto mais que, parecem ser os investigadores de áreas científicas afins, e como tal pretensos seguidores de uma mesma linha de pensamento eminentemente racional (lógico), os grandes supreendidos pelas verdadeiras inovaçð̄es científicas. Kuhn e a sua concepção de revolução científica, aplicada à ciência "extraordinária», apresenta, sem dúvida, algumas afinidades com a Epistemologia de Bachelard.

\section{$O$ critério de perfectibilidade em Química}

No decurso dos tempos foi sempre possivel afirmar que a Natureza é um campo inesgotável de descoberta científica. Uma análise comparativa do sentido de inesgotável no século XVIII e no século XX conduzir-nos-ia à constatação de que, no primeiro, o termo deve ser associado a variedade, enquanto que, no segundo, a profundidade. A abundância de factos naturais e imediatos tem muito pouco a ver com os interesses da Química 
contemporânea. Caracterizaçōes físicas superficiais de um objecto constituem mais um obstáculo do que um estímulo ao progresso da ciência química. $\mathrm{O}$ químico contemporâneo não incorre no erro de classificar como conhecimento científico o conhecimento de primeira instância, impõe-lhe antes um critério de perfectibilidade, organiza-o racionalmente, valoriza-o e valoriza a ciência.

Uma das grandes revoluçø̃es ideológicas que renovaram a ciência química deve-se, como atrás se afirmou, a Mendéléeff ao enquadrar coerentemente o conjunto disperso das substâncias simples, os elementos; em tempo anterior, coubera a Lavoisier papel semelhante ao iniciar a era da química analítica. A passagem da noção de massa atómica para a de número atómico na organização dos elementos químicos foi verdadeiramente inovadora, o salto dinamizador da Química contemporânea. $\mathrm{Na}$ época de Mendéléeff, porém, o número atómico não passava de um numeral ordinal, um número que fixava a ordem de inscrição de cada elemento na Tabela Periódica. Com o conhecimento da estrutura do átomo, o conceito de número atómico valorizou-se, passou de ordinal a cardinal, tomou a expressão do número dos electrōes (ou dos protōes) de qualquer átomo do mesmo elemento. O número atómico é, hoje, um valor teórico. A análise das múltiplas teorias e organizaçס̃es técnicas que assentam na noção de número atómico (ou de electrão) permite concluir que a actual sistematização da Química se reveste de um carácter filosófico novo, o de Materialismo Racional.

A noção de valência foi igualmente valorizada, o seu significado profundo encontrado. De facto, a ordenação da Tabela Periódica, com base na estrutura electrónica dos átomos, faz completo sentido: nos períodos, os elementos colocam-se por ordem crescente do número dos seus electrōes e, nas famíliąs, situam-se os elementos que têm igual número de electrõs na camada periférica (e crescente, em quantidade compreensível, no cerne do átomo).

«O quadro de Mendéléeff, reorganizado ao nível dos conhecimentos actuais, acede a um verdadeiro racionalismo aritmético da matéria" [11].

Outro exemplo interessante de aplicação do critério de perfectibilidade no conhecimento químico prende-se com o significado é evolução das fórmulas moleculares e estruturais dos compostos. A molécula de água, por exemplo, é susceptivel das seguintes repreșentaçðes:
$\mathrm{H}_{2} \mathrm{O}$

$$
\mathrm{H}-\mathrm{O}-\mathrm{H}
$$
(b)
(c)
(d)
(e)
(a)

(b)

De qualquer das fórmulas se pode inferir a constituição da água: dois átomos de hidrogénio e um de oxigénio. A fórmula (a), porém, nada indica quanto ao modo de ligação daqueles três átomos. As fórmulas (b) a (f), pelo contrário, são claras na indicação de que cada átomo de oxigénio se liga a dois átomos de hidrogénio. A formula (b) em relação à (a) apresenta esse, e só esse, acréscimo de informação. $\mathrm{O}$ eminente químico Lewis introduziu nas fórmulas dos compostos o símbolo :, electrónico, com o sentido de mostrar que as ligaçōes eram feitas por partilha de dois electrões, além de identificar o número de pares de electrōes livres (não compartilhados) existentes na camada externa dẹ átomo. Assim, a leitura química da fórmula (c) valorizou o conhecimento das ligaçðes entre os átomos da molécula de água ao informar-nos de que se tratam de ligações covalentes (formadas por partilha de dois electrōes) e, ainda, de que o átomo de oxigénio tem dois pares de electrões livres que poderá, eventualmente, partilhar com outro átomo por covalência dactiva, isto é, legando ele próprio os dois electrões para uma possível terceira ligação. Implictamente ficou justificada a estrutura de um dos mais importantes iðes da Química, o ião hidrónio, $\mathrm{H}_{3} \mathrm{O}^{+}$:

$$
\left[\begin{array}{l}
\mathrm{H}: \underset{\mathrm{O}}{\because}: \mathrm{H} \\
\mathrm{H}
\end{array}\right]^{+}
$$

Em (d), por proposta de Robinson, o simples traço de união passou a ter o mesmo significado que os dois pontos. Em (e), o traço radial, no caso dos pares de electrões livres, foi tranformado em traço tangencial, de acordo com o simbolismo de Eistert. Tanto a fórmula (d) como a (e) não acrescentam profundidade ao conhecimento; simplificam, todavia, a sua leitura. Por fim, a fórmula (f) introduz um novo incremento de saber: o ângulo da ligação. Enquanto que os presumíveis $180^{\circ}$ do ângulo HÔH nas fórmulas (a) a (e) não manifestam o verdadeiro ângulo de ligação, os $109^{\circ}$ da fórmula (f) indicam a genuína disposição dos átomos na molécula da água. Esta curta história da representação da molécula da água ilustra os saltos qualitativos que compõem o progresso da ciência. Ao simbolismo rectificado corresponde uma maior profundidade epistemológica, uma vez que o real científico só é conseguido por sucessivas aproximações de grau de precisão crescente.

\section{A Modernidade da Química}

A Química começou por ser um amontoado informe de factos, cujo conhecimento sugeria mais um exercício de memória do que uma expressão de faculdades intelectivas. $\mathrm{O}$ encadeado lógico dos factos, a possível previsão de uns a partir de outros, foi o primeiro passo para a sua modernização: o empirismo científico decresceu.

Após um paralelismo de atitudes e mesmo de objectos de estudo do química experimentalista e do químico teórico, após a revolução científica do princípio do século $\mathrm{XX}$ que interpenetrou fenómenos da matéria, essencialmente do dominio experimental, com leis de energia, essencialmente do domínio teórico, assistiu-se a uma convergência, a um verdadeiro diálogo científico entre estes dois parceiros, os quais procuram agora discutir o mesmo problema, trocar sobre ele explicações inteligiveis e complementares. A esta dialéctica teoria-experiência se deve a aceleração do progresso da Química da era pós-moderna.

O facto experimental é um "facto de cultura», assim envolvido por uma perspectiva teórica, fruto de uma memória racional; a teoria, por seu lado, é sujeita a exame experimental permanente. A previsão de um novo fenómeno pela razão estimula a pesquisa experimental, acorda o presente na técnica: porque o instrumento é um intermediário indispensável ao estudo do fenómeno; porque o instrumento tem destinação teórica; porque a realidade técnica é a afirmação do valor objectivo da ciência.

De Bröglie postulou para a matéria propriedades ondulatórias. A Mecânica Ondulatória associou ao electrão, partícula material, uma onda cujo comprimento de 
onda, em condiçð̃es específicas, seria comparável ao dos raios X. A construção de aparelhagem adequada permitiu a Thompson, Davisson e Germer, demonstrar a teoria formulada. O microscópio electrónico, com feixe de electrões ao invés de feixe luminoso, com uma ampliação poderosa que distingue a molécula, é a realização técnica de valor incalculável que a ciência produziu.

Ao dualismo da actividade química, teórica e experimental, corresponde um fecundo campo de interseç̧ão das duas grandes vias filosóficas, empirista e racionalista, num contexto contemporâneo. Bachelard explicou claramente o significado desta intersecção na sua proposta epistemológica: um racionalismo nem rígido nem abstracto, antes aberto e solidário com a informação de raiz empírica, precisa e pormenorizada; um racionalismo aplicado, produtor e organizador do pensamento técnico.

Bachelard propos ao filósofo «meditar sobre o pensamento científico contemporâneo" (19]. Althusser, por seu lado, afirma que "cada cientista acalenta em si um filósofo adormecido" [15]. Sem pretender fundir, como era regra na Antiguidade, Filosofia e Ciência, a verdade é que, em pleno século XX, o filósofo apresenta um pendor particular para pensar a ciência e, é detectável no cientista certa forma de filosofia espontânea, no sentido de não consciente.

Há, pois, uma relação actual extraordinária entre a Filosofia e a Ciência, uma complementaridade, cujo alimento terá, necessariamente, de ultrapassar linguagens diversificadas por centenas de anos. O filósofo do Materialismo Racional utiliza comummente a tríada teoria-objecto-método; o químico, ao expressar um conjunto de sentido semelhante, recorrerá aos termos modelo-experiência-técnica. Existem, porém, ainda no domínio da linguagem, interaç̧ðes prometedoras: o Atomismo Lógico de Russell, as suas proposições atómicas (ou elementares) e moleculares correspondentes às qualidades dos objectos e relações entre eles, os factos atómicos (elementos simples) e moleculares [16]; a proposta da Filosofia Analítica de Wittgenstein, o seu «jogo linguístico", o significado do conceito de elemento simples e de composto, a função do filósofo de «devolver as palavras do seu uso metafísico ao seu uso diário" [17].

A especialização aconteceu, com uma força inusitada, a meio deste século. Ela foi a manifestação de uma necessidade da cultura científica, a ultrapassagem do conhecimento geral, das simples afirmaçð̃es iniciais. O pensamento científico especializado é uma actualidade e reveste-se de aspectos francamente positivos: é mais aberto à rectificação de ideias e de processos do que o pensamento generalista, tradicional e rotineiro; aplica os seus trunfos em zonas de fronteira das ciências; progride, em consequência, a um ritmo muito elevado. $\mathrm{O}$ exemplo mais flagrante deste fenómeno científico teve lugar na área limítrofe da Química tradicional. Com o auxílio da nova Física, por um lado, e da Biologia, por outro, originaram-se àreas disciplinares novas, a Química-Física e a Bioquímica, respectivamente.

A Química actual é inconcebível sem uma teorização adequada. A Química Teórica, um dos seus ramos mais modernos e de maior índice de desenvolvimento, é fruto de uma racionalização do conhecimento.

"De fácil, a Química, tornou-se, subitamente, difícil» [11]. Bachelard assim expressou a modernidade da Química: do elementarismo de séqulos para a complexidade actual; da memorização para a compreensão; de uma ciência estática para uma cultura atractiva, dinâmica, de objectividade definida e avanço tecnológico.

\section{Referências}

[1] F. Dagognet, «Bachelard», Presses Universitaires de France. 1965 (ed. portuguesa: «Bachelard», ed. 70, 1986.

[2] G. Bachelard, "Essai sur la connaissance approchée», ed. Vrin, 1928.

[3] G. Bachelard, "Étude sur la evolution d'un probléme de Physique: La propagation thérmique dans les solidesn, ed. Vrin, 1929.

[4] G. Bachelard, "La valeur inductive de la relactivité", ed. Vrin, 1929.

[5] G. Bachelard, "Le pluralisme cohérent de la Chimie moderne", ed. Vrin, 1932.

[6] G. Bachelard, «Le nouvel esprit scientifique», Presses Universitaires de France, 1934 (ed. portuguesa: $« O$ novo espirito cientifico", ed. 70,1986 ).

[7] G. Bachelard, «La formation de l'esprit scientifiquem, ed. Vrin, 1938.

[8] G. Bachelard, «La Philosophy du non», Presses Universitaires de France, 1940 (ed. portuguesa: «A Filosofia do não, Filosofia do novo espírito cientifico», Presença, 1976).

[9] G. Bachelard, "Le rationalisme appliqué», Presses Universitaires de France, 1949.

[10] G. Bachelard, "L'activité rationaliste de la Physique contemporainem, Presses Universitaires de France, 1951.

[11] G. Bachelard, "Le materialisme rationnel», Presses Universitaires de France, 1953.

[12] J.F. Mora, "Diccionario de Filosofia abreviado", Ed. Sudamericana, 1974 (ed. portuguesa: «Dicionário de Filosofia», Publ. Dom Quixote, 5." ed., 1982).

[13] G. Bachelard, «L'épistémologie», Presses Universitaires de France, 1971 (ed. portuguesa: «A epistemologia», ed. 70, 1984).

[14] E. Meyerson, "Identité et realité», ed. Vrin, 1908.

[14] L. Althusser, «Philosophie et philosophie spontanée des savants», Librarie François Maspero, 1974 (ed. portuguesa: «Filosofia e filosofia expontânea para cientistas", Presença, 1979).

[16] B. Russell, "A filosofia do atomismo lógico", ed. George Allen and Urwin, 1918.

[17] L. Wittgenstein, «Philosophical Investigations», Basil Blackwell and Mott, 1985 (ed, portuguesa: «Tratado lógico-filosófico • Investigações filosóficas", Fundação Calouste Gulbenkian, 1987).
POTÁSSIO, de potassa, uma forma impura de carbonato de potássio conhecida desde tempos remotos; o símbolo K deriva do seu nome latino Kalium; descoberto em 1807; é o sétimo elemento mais abundante na crosta terrestre. A sua radioactividade, apesar de fraca, pode ser uma das causas naturais das mutações genéticas no homem.

CÁLCIO, de calx, ou cal (óxido de cálcio); descoberto em 1808; é o quinto mais abundante elemento da crosta terrestre. A sua presença nos nossos corpos é essencial. A quantidade normal num adulto é cerca de $1 \mathrm{~kg}$ encontrando-se, a maior parte, nos dentes e nos ossos. O cálcio também tem um papel importante na regulação do batimento cardíaco. 